\title{
PENGARUH KOORDINASI KERJA, KOMUNIKASI SERTA SEMANGAT KERJA TERHADAP PRESTASI KERJA KARYAWAN PADA PT. TELKOMSEL SALES OUTLET OPERATION RANTAUPRAPAT
}

\author{
Deade Putri Arika' ${ }^{1}$, Hj. Siti Lam'ah Nasution ${ }^{2}$
}

Alumni Sarjana Ekonomi STIE Labuhanbatu ${ }^{2}$ Dosen STIE Labuhanbatu

\begin{abstract}
ABSTRAK
Tujuan dari penelitian ini adalah untuk mengetahui pengaruh koordinasi kerja, komunikasi, dan semangat kerja terhadap pretasi kerja karyawan pada PT. Telkomsel Sales Outlet Operation Rantauprapat, baik secara parsial maupun secara simultan. Pengumpulan datamenggunakan wawancara, kuesioner dan studi pustaka. Pengerjaan metodeanalisis data dengan menggunakan bantuan software SPSS 20.0 for Windows.Penelitian inimenggunakan sampel sebanyak 44orang karyawan yang diambil denganmenggunakan teknik sensus. Hasil penelitian berdasarkan uji secara serempak (uji F) menunjukkan bahwa secara simultan (serempak)koordinasi kerja, komunikasi, dan semangat kerjaberpengaruh positif dan signifikan terhadap pretasi kerja karyawan pada PT. Telkomsel Sales Outlet Operation Rantauprapat, dimana Fhitung $(13,425)>$ Ftabel $(2,84)$ dengan signifikansi $0,000<0,05$. Hasil pengujian hipotesis secara parsial (uji t) menunjukkan bahwa koordinasi kerja $\left(\mathrm{X}_{1}\right)$ berpengaruh positif dan signifikan terhadap pretasi kerja karyawan pada PT. Telkomsel Sales Outlet Operation Rantauprapat, dimana thitung $(3,086)>\operatorname{tabel}(1,68385)$ dengan signifikansi $0,004<0,05$.Komunikasi $\left(\mathrm{X}_{2}\right)$ berpengaruh positif dan signifikan terhadap pretasi kerja karyawan pada PT. Telkomsel Sales Outlet Operation Rantauprapat, dimana thitung $(2,839)>$ tabel $(1,68385)$ dengan signifikansi $0,007<0,05$. Semangat kerja $\left(\mathrm{X}_{3}\right)$ berpengaruh positif dan signifikan terhadap pretasi kerja karyawan pada PT. Telkomsel Sales Outlet Operation Rantauprapat, dimana thitung(2,228)> tabel(1,68385) dengan signifikansi $0,032<0,05$.Berdasarkan hasil uji determinasi diketahui bahwa 50,2\% prestasi kerja karyawan dapat di jelaskan oleh variabel koordinasi kerja,komunikasi dan semangat kerja. Sedangkan sisanya 49,8\% dapat dijelaskan oleh faktor-faktor lain yang tidak diteliti dalam penelitian ini, seperti gaya kepemimpinan, motivasi, budaya organisasi, dan lain sebagainya.
\end{abstract}

Kata kunci : Koordinasi kerja, Komunikasi, Semangat kerja, Prestasi kerja.

hendakdicapai. Setiap organisasi mempunyai keterbatasan

akan sumber daya manusia, uang dan fisik untuk mencapai tujuan organisasi. Keberhasilan mencapai tujuan tergantung pada pemilihan tujuan yang akan dicapai dengan cara menggunakan sumber daya untuk mencapai tujuan organisasi sesuai dengan apa yang diharapkan, maka salah 
satu aspek yang diperhatikan adalah faktor manusia. Tanpa adanya kerjasama sulit bagi organisasi untuk mencapai sukses dan adapun kiranya untuk mencapai tujuan tersebut organisasi atau perusahaan seharusnya turut membantu menciptakan prestasi kerja karyawan. Dalam upaya mencapai prestasi kerja karyawan yang tinggi, sangat diperlukan terjalinnya komunikasi yang baik antar unit yang ada dalam perusahaan tersebut, baik komunikasi antara pimpinan dan bawahan secara timbal balik yang dapat terlihat dalam penilaian prestasi kerja karyawan, maupun komunikasi antara karyawan yang dapat terlihat dari koordinasi yang dilakukan dalam melaksanakan tugas sehari-hari.

Prestasi kerja seorang karyawan dalam sebuah perusahaan dapat dilihat dari tingkat kecakapan seseorang pada tugas-tugas yang mencakup pada pekerjaannya. Artinya beban kerja yang ditetapkan tercapai atau realisasi hasil lebih tinggi daripada yang telah ditetapkan perusahaan. Untuk mencapai tujuan yang diinginkan dengan efektif, seluruh sumber daya yang ada dalam organisasi harus dapat dimanfaatkan sebaik mungkin termasuk sumber daya manusia sebagai alat utamanya Sehingga suatu organisasi dituntut mampu menyediakan sejumlah karyawan yang sesuai dengan jenis dan beban kerja yang ada.

Akan tetapi karyawan yang ada belumlah cukup sehingga perlu adanya koordinasi kerja untuk menciptakan terjadinya keselarasan antara tugas dan pekerjaan yang dilakukan oleh seseorang atau bagian yang satu dengan bagian yang lain, koordinasi sangat diperlukan.

Koordinasi adalah kegiatan mengarahkan, mengintegrasikan dan mengkoordinasikan unsur-unsur manajemen dan pekerjaan-pekerjaan para bawahan dalam mencapai tujuan organisasi. Dengan adanya koordinasi akan tercipta keselarasan kerja antara anggota organisasi sehingga tidak terjadi kesimpang siuran dan tumpang tindih pekerjaan. Dalam koordinasi dimana suatu organisasi bekerja sama dengan baik dalam mekanisme kerja, sangat tergantung pada hubungan timbal balik antar pimpinan dengan para staf maupun sesama karyawan.

Komunikasi sangat penting untuk menjalin hubungan kerja sama antara karyawan yang terlibat dalam suatu perusahaan dan mempunyai pengaruh yang sangat besar dalam proses pencapaian tujuan perusahaan tersebut. Komunikasi akan memungkinkan setiap karyawan yang berada di perusahaan untuk saling membantu dan mengadakan interaksi. Komunikasi akan berhasil apabila pengirim pesan dan penerima pesan sama-sama mencapai pengertian dan kesimpulan yang sama sesuai dengan yang dimaksudkan, tentang apa yang sebenarnya di sampaikan.

Semangat kerja adalah keinginan dan kesungguhan seseorang mengerjakan pekerjaannya dengan baik serta berdisiplin untuk mencapai kecakapan yang maksimal. Semangat kerja ini akan merangsang

Seseorang untuk berkarya dan berkreativitas dalam pekerjaannya. Semangat kerja atau gairah melakukan pekerjaan dengan lebih giat maka pekerjaan akan dapat diharapkan lebih baik. Karyawan yang mempunyai semangat kerja yang tinggi akan dampak terhadap sikap yang mau 
sepenuhnya memanfaatkan keterampilan, konsentrasi pekerja serta kemapuan-kemampuan lain yang dimilikinya untuk dapat melakukan tugas dengan sebaik-baiknya sehingga berpengaruh terhadap peningkatan prestasi kerja.

Berdasarkan latar belakang yang dikemukakan diatas, maka penulis tertarik untuk melakukan penelitian pada

PT. TelkomselSales Outlet Operation

Rantauprapat dengan judul "Peranan Koordinasi Kerja, Komunikasi Serta Semangat Kerja Terhadap Prestasi Kerja Karyawan Pada PT. Telkomsel Divisi Sales Outlet Operation Rantauprapat”.

\section{Uraian Teori Koordinasi}

Koordinasi adalah proses

pengintegrasian tujuan-tujuan dan kegiatan-kegiatan pada satuan-satuan yang terpisah(departemen-departemen atau bidang-bidang fungsional) pada suatu organisasi untuk mencapai tujuan secara efisien danefektif.

Komunikasi komunikasi adalah prosespemindahan pengertian dalam bentuk gagasan atau komunikasi dari seseorang ke orang lain.

Semangat Kerja semangat kerja adalahkeinginan dan kesungguhan seseorang mengerjakan pekerjaannya dengan baik serta berdisiplin untuk mencapai prestasi kerja yang maksimal.

\section{Prestasi Kerja}

Prestasi kerja (performance) dapat diartikan sebagai hasil kerja yang dicapai

oleh seseorang atau kelompok (organisasi) dalam waktu tertentu.

\section{Kerangka Konseptual}

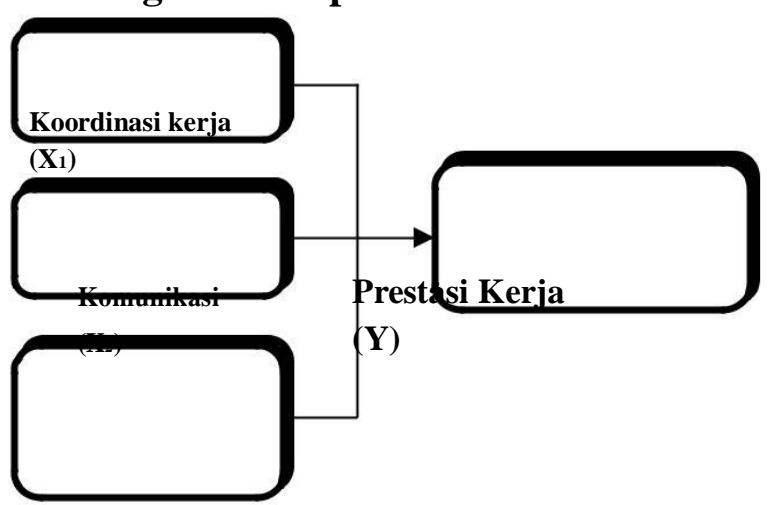


Semangat Kerja

( $\left.\mathbf{X}_{3}\right)$

\section{Gambar 1 Kerangka Konseptual Hipotesis}

Hipotesis merupakan jawaban sementara terhadap rumusan masalah penelitian (Sugiyono, 2012:93). Berdasarkan perumusan masalah dan kerangka konseptual, maka hipotesis dalam penelitian ini adalah:

Koodinasi kerja berpengaruh positif dan signifikan terhadap prestasi kerja karyawan pada PT. Telkomsel Sales Outlet Operation Rantauprapat.

Komunikasi berpengaruh positif dan signifikan terhadap prestasi kerja karyawan pada PT. Telkomsel Sales Outlet Operation Rantauprapat.

Semangat kerjaberpengaruh positif dan signifikan terhadap prestasi kerja karyawan pada PT. Telkomsel Sales Outlet Operation Rantauprapat.

Koordinasi kerja, komunikasi, dan semangat kerja berpengaruh positif dan signifikan terhadap prestasi kerja karyawan pada PT. Telkomsel Sales Outlet Operation Rantauprapat.

\section{METODE PENELITIAN Populasi}

Populasi pada penelitian ini adalah seluruh karyawan PT.

Telkomsel Divisi Seles Outlet

Operation

Rantauprapat yang berjumlah 44 orang.

\section{Sampel}

Sampel adalah suatu himpunan bagian dari unit populasi. Metode pengambilan sampel menggunakan metode sensus dimana semua anggota populasi menjadi sampel. Alasan dilakukannya penarikan sampel secara sensus adalah karena kecilnya jumlah populasi yang ada ditempat dimana diadakan pengujian. Dengan demikian jumlah sampel adalah sebesar populasi yaitu 44 orang. 
mengetahui nilai-nilai variabel, baik satu variabel ataupun lebih tanpa membuat perbandingan atau menghubungkan dengan variabel lain dan untuk mengetahui nilai dari fenomena yang terjadi pada suatu organisasi/perusahaan.

\section{Analisis Regresi Linear Berganda}

Analisis regresi digunakan untuk mengetahui bagaimana variabel dependent dapat diprediksi melalui variabel independent secara individual.

\section{Uji Hipotesis Uji Signifikansi Parsial (Uji t) Jenis dan Sumber Data}

Data yang digunakan dalam penelitian ini adalah :

Data kualitatif, yaitu data dalam bentuk kata-kata, penjelasan, pernyataan dan bukan dalam bentuk angka.

Data kuantitatif, yaitu data dalam bentuk angka-angka atau bilangaN.

Sumber data dalam penelitian ini adalah :

Data primer

Data sekunder

\section{Teknik Pengumpulan Data}

Teknikyang digunakan untuk pengumpulan data penelitian

meliputi :

Observasi

Wawancara

Kuesioner

Metode Analisis Data Metode Analisis Deskriptif 
Metode penelitian deskriptif adalah penelitian yang dilakukan untuk Uji t bertujuan untuk mengetahuibesarnya pengaruh masing-masing variabel independent secara individu (parsial) terhadap variabel dependent.

\section{Uji Signifikansi Simultan (Uji F)}

Uji $\mathrm{F}$ bertujuan untuk mengetahui Pengaruh secara serentak atau bersamasama variabel independent (Koordinasi dan Komunikasi serta Semangat kerja) terhadap variabel dependent (Prestasi Kerja).

\section{Koefisien Determinasi $\left(\boldsymbol{R}^{2}\right)$}

Koefisien determinasi bertujuan untuk mengukur seberapa jauh kemampuan model dalam menerangkan variasi variabel independent atau predictor-nya.

\section{HASIL PENELITIAN DAN PEMBAHASAN Hasil Penelitian Analisis Regresi Linear Berganda}

Metode analisis regresi berganda digunakan untuk mengetahui berapa besar pengaruh variabel bebas (Koordinasi

Kerja, Komunikasi dan Semangat Kerja) terhadap variabel terikat (Prestasi Kerja Karyawan). Data diolah secara statistik untuk keperluan analisis dan pengujian hipotesis dengan menggunakan alat bantu program SPSS 20.0 for windows.

\section{Tabel 1 Hasil Regresi Linear}

\section{Berganda}

Coefficients $^{\mathrm{a}}$

\begin{tabular}{|c|c|c|c|c|c|}
\hline \multirow{2}{*}{ Model } & \multicolumn{2}{|c|}{$\begin{array}{l}\text { Unstandardize } \\
\text { d Coefficients }\end{array}$} & \multirow{2}{*}{\begin{tabular}{|l}
$\begin{array}{l}\text { Standardized } \\
\text { Coefficients }\end{array}$ \\
Beta
\end{tabular}} & & \multirow{2}{*}{ Sig. } \\
\hline & $B$ & $\begin{array}{l}\text { Std. } \\
\text { Error }\end{array}$ & & & \\
\hline (Constant) & 1,673 & 3,058 & & 547 & 587 \\
\hline Koordinasi & 353 &, 114 & 392 & $\beta, 086$ & 004 \\
\hline $\begin{array}{l}1 \\
\text { Komunikasi }\end{array}$ & 307 &, 108 & 361 & 2,839 & 007 \\
\hline Semangat krja & 275 &, 123 & .249 & 2,228 & 032 \\
\hline
\end{tabular}

a. Dependent Variable: Prestasi kerja

Berdasarkan Tabel 1 diketahui pada kolom kedua (unstandardizedCoefficients) bagian B, diperoleh nilaikoefisien regresi $b_{1}$ (variabel koordinasi kerja)sebesar 0,353, b2 (variabel komunikasi) sebesar 0,307, b3 (semangat kerja) sebesar 0,275 dan nilai konstanta 
(a) adalah 1,673.Maka diperoleh persamaan regresi linier berganda sebagai berikut :

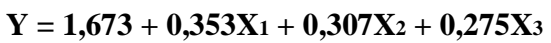

kordinasi kerja $\left(\mathrm{X}_{1}\right)$ ditingkatkan sebesar satu satuan, maka prestasi kerja akan meningkat sebesar 0,353 .

Koefisien $\mathrm{X}_{2}\left(\mathrm{~b}_{2}\right)=0,307$, ini berarti bahwa variabel komunikasi $\left(\mathrm{X}_{2}\right)$ berpengaruh positif terhadap prestasi kerja, atau dengan kata lain jika komunikasi $\left(\mathrm{X}_{2}\right)$ ditingkatkan sebesar satu satuan, maka prestasi kerja akan bertambah sebesar 0,307.

Koefisien $\mathrm{X}_{3}\left(\mathrm{~b}_{3}\right)=0,275$, ini berarti bahwa variabel semangat kerja $\left(\mathrm{X}_{3}\right)$ berpengaruh positif terhadap prestasi kerja, atau dengan kata lain jika semangat kerja $\left(\mathrm{X}_{3}\right)$ ditingkatkan sebesar satu satuan, maka prestasi kerja tidak akan meningkat sebesar 0,275.

Pengujian Hipotesis Uji Signifikansi Parsial (Uji t)Uji t dilakukan untuk menguji secara parsial apakah koordinasi kerja $\left(\mathrm{X}_{1}\right)$,komunikasi $\left(\mathrm{X}_{2}\right)$ dan semangat kerja $\left(\mathrm{X}_{3}\right)$ secara parsial atau individual berpengaruh signifikan terhadap prestasi kerja karyawan pada PT. Telkomsel Sales Outlet Operation Rantauprapat (Y). Hasil uji t dapat dilihat pada Tabel 2 sebagai berikut ini :

Berdasarkan persamaan

diatas maka dapat diuraikan sebagai berikut :

a. $\quad$ Konstanta (a) = 1,673 menunjukkan nilai konstan, jika nilai variabel bebas (koordinasi kerja, komunikasi dan semangat kerja) $=0$ maka prestasi kerja $(Y)$ akan sebesar 1,673

Koefisien $\mathrm{X}_{1}\left(\mathrm{~b}_{1}\right)=0,353$, ini berarti bahwa variabel koordinasi kerja $\left(\mathrm{X}_{1}\right)$ berpengaruh positif terhadap prestasi kerja, atau dengan kata lain jika

\section{Tabel 2 Hasil}

\section{Uji t}

Coefficients $^{\mathrm{a}}$

\begin{tabular}{|c|c|c|c|c|c|}
\hline \multirow{2}{*}{ Model } & \multicolumn{2}{|c|}{$\begin{array}{l}\text { Unstandardize } \\
\text { d Coefficients }\end{array}$} & \multirow{2}{*}{$\begin{array}{l}\text { Standardized } \\
\text { Coefficients }\end{array}$} & & \multirow{2}{*}{ Sig. } \\
\hline & $B$ & $\begin{array}{l}\text { Std. } \\
\text { Error }\end{array}$ & & & \\
\hline (Constant) & 1,673 & 3,058 & & 547 & 587 \\
\hline Koordinasi & 353 & 114 & 392 & 3,086 & 004 \\
\hline Komunikasi & 307 & 108 & 361 & 2,839 & 007 \\
\hline Semangat krja & 275 & 123 & 249 & 2,228 & 032 \\
\hline
\end{tabular}


thitung $(2,228)>$

Melalui Tabel 2 hasil uji signifikan secara parsial dapat diambil kesimpulan yaitu:

Variabel koordinasi kerja mempunyai angka signifikansi sebesar 0,004<0,05

yang artinya bahwa variabel koordinasi kerja secara parsial berpengaruh signifikan terhadap prestasi kerja karyawan. Untuk melihat diterima atau ditolaknya sebuah hipotesis juga bisa dilakukan dengan membandingkan nilai thitung dengan tabel. Jika thitung $>$ tabel, maka hipotesis diterima. Dalam hal ini thitung $(3,086)>$ tabel $(1,68385)$ maka variabel koordinasi kerja secara individual berpengaruh signifikan terhadap prestasi kerja karyawan PT. Telkomsel Sales Outlet Operation Rantauprapat.

Variabel komunikasi mempunyai angka signifikansi sebesar $0,007<0,05$ yangartinyabahwavariabel

komunikasi secara parsial berpengaruh signifikan terhadap prestasi kerja karyawan. Untuk melihat diterima atau ditolaknya sebuah hipotesis juga bisa dilakukan dengan membandingkan nilai thitung dengan tabel. Jika thitung $>$ ttabel, maka hipotesis diterima. Dalam hal ini thitung $(2,839)>$ tabel $(1,68385)$ maka variabel komunikasi secara parsial berpengaruh signifikan terhadap prestasi kerja karyawan PT. Telkomsel Sales Outlet Operation Rantauprapat.

Variabel semangat kerja mempunyai angka signifikansi sebesar $0,032<0,05$ yang artinya bahwa variabel semangat kerja secara parsial berpengaruh signifikan terhadap prestasi kerja karyawan. Untuk melihat diterima atau ditolaknya sebuah hipotesis juga

bisa dilakukan denganmembandingkan nilai $\mathrm{t}$ thitung dengan ttabel. Jika thitung >ttabel, maka hipotesis diterima.

Dalam hal ini

ttabel(1,68385) maka variabel semangat kerja secara parsial berpengaruh signifikan terhadap prestasi kerja karyawan PT. Telkomsel Sales Outlet Operation Rantauprapat.

\section{Uji Signifikansi Simultan (Uji F)}

Pengujian ini dilakukan untuk melihat secara bersama-sama pengaruh atau hubungan positif dan signifikan variabel bebas $\left(\mathrm{X}_{1}, \mathrm{X}_{2}, \mathrm{X}_{3}\right)$ berupa koordinasi kerja, komunikasi dan semangat kerja terhadap variabel terikat

berupa prestasi kerja karyawan pada PT. Telkomsel Sales Outlet Operation Rantauprapat. 


\section{Tabel 3 Hasil}

\section{Uji F}

ANOVA $^{\mathrm{a}}$

\begin{tabular}{|l|l|l|l|l|l|}
\hline Model & $\begin{array}{l}\text { Sum of } \\
\text { Squares }\end{array}$ & df & $\begin{array}{l}\text { Mean } \\
\text { Square }\end{array}$ & F & Sig. \\
\hline $\begin{array}{l}\text { Regression } \\
1\end{array}$ & 57,652 & 3 & 19,217 & 5 & 13,42 \\
Residual & 57,257 & 40 & 1,431 & & \\
Total & 114,909 & 43 & & & \\
\hline
\end{tabular}

b. Predictors: (Constant), Semangat krja, Komunikasi, Koordinasi Melalui uji ANOVA atau F-test pada Tabel 3, diperoleh nilai Fhitung sebesar 13,425 dengan tingkat signifikansi 0,000. Maka Fhitung $(13,425)>F_{\text {tabel }}$ $(2,84)$ dengan signifikansi $0,000<0,05$. Berdasarkan hasil tersebut apat disimpulkan bahwa variabel koordinasi kerja, variabel komunikasi dan variabel prestasi kerja secara simultan berpengaruh signifikan terhadap prestasi kerja karyawan PT.

Telkomsel Sales Outlet Operation Rantauprapat.

\section{Koefisien Determinasi}

Hasil pengujian koefisien determinasi menggunakan SPSS Statistic 0 for windows dapat dilihat pada Tabel 12 dibawah ini:

\section{Tabel 4 Koefisien}

\section{Determinasi}

Model Summary

\begin{tabular}{|l|l|l|l|l|}
\hline Model & R & R Square & $\begin{array}{l}\text { Adjusted } \\
\text { R Square }\end{array}$ & $\begin{array}{l}\text { Std. Error } \\
\text { of the } \\
\text { Estimate }\end{array}$ \\
\hline 1 & $708^{\mathrm{a}}$ &, 502 &, 464 & 1,196 \\
\hline
\end{tabular}

a. Predictors: (Constant), Semangat krja, Komunikasi, Koordinasi

Nilai $R$ sebesar 0,708 berarti hubungan antara variabel kordinasi kerja $\left(\mathrm{X}_{1}\right)$, komunikasi $\left(\mathrm{X}_{2}\right)$ dan prestasi kerja $\left(\mathrm{X}_{3}\right)$ terhadap variabel prestasi kerja karyawan $(\mathrm{Y})$ sebesar 70,8 \% artinya hubungannya erat.

Nilai $R$ Square 0,502 berarti 50,2\% prestasi kerja karyawan dapat di jelaskan oleh variabel koordinasi kerja,komunikasi dan semangat kerja. Sedangkan sisanya 49,8 \% dapat dijelaskan 
oleh faktor-faktor lain yang tidak diteliti dalam penelitian ini, seperti gaya kepemimpinan, motivasi, budaya organisasi, dan lain sebagainya.

Standard Error of the Estimate artinyamengukur variasi dari nilai yang diprediksi. Nilai Standard Error of theEstimateadalah 1,196. Semakin kecilnilai Standard Error of the

Estimatesemakin baik.

\section{Saran}

Berdasarkan hasil penelitian dan evaluasi, maka saran yang dapat diberikan penulis adalah sebagai berikut :

Dalam hal koordinasi kerja, yang harus diperhatikan perusahaan ialah bagaimana menciptakan agar dalam melaksanakan pekerjaan karyawan mengikuti arahan dari pimpinan agar memberikan hasil yang maksimal.

Manajemen perusahaan harus memperhatikan bagaimana menciptakan komunikasi yang baik dalam perusahaan agar menciptakan hasil yang maksimal.Pimpinan harus memberikan pujian apabila karyawan layak untuk mendapatkanya agar karyawan merasa diperhatikan dan dihargai. Selain itu pimpinan harus mampu menjelaskan prosedur untuk setiap pekerjaan yang dilaksanakan oleh karyawan. pada saat yang tepat.

Pihak manajemen perusahaan harus mampu menumbuhkan semangat kerja karyawan, yang dapat yang dilakukan adalah dengan pendekatan secara langsung oleh pimpinan yang sifatnya membina atau mengajak serta menjadi contoh bagi karyawan agar semangat kerja karyawan timbul dalam menyelesaikan tanggung jawabnya dalam pekerjaan sehingga dapat meningkatkan prestasi kerja mereka.

Bagi peneliti selanjutnya diharapkan agar dapat terus mengembangkan penelitian ini dengan menambah variabel lainnya sehingga dapat mengukur prestasi kerja karyawan secara lebih mendalam. 
DAFTAR PUSTAKA

Adelina, Marina. 2011.

Pengaruh Semangat Kerja Dan

Disiplin KerjaTerhadap

Prestasi Kerja Karyawan

Pada Perum Pegadaian Kanwil I

Medan. Skripsi (Tidak dipublikasi).

Medan : FE USU.

Daft L, Richard. 2007. Manajemen.

Jakarta : Erlangga.
Handoko, T. Hani. 2009. Manajemen.

Edisi Kedua. BPFE:Yogyakarta.

Personalia Dan Sumber Daya

Manusia. Edisi Kedua. Cetakan

Kelimabelas. BPFE. Yogyakarta.

Hasibuan, Malayu S. P.

2006. Manajemen Dasar,

Pengertian, dan Masalah. Edisi

Revisi. Bumi Aksara: Jakarta.

2009. Manajemen 
Devi, Khosyalia. 2012. Pengaruh

Koordinasi

Dan Pendelegasian

Wewenang Terhadap Prestasi Kerja

Karyawan Pada Bagian Sumber

Daya Manusia (SDM) PT.

Perkebunan Nusantara IV (Persero)

Medan. Tesis (Tidak dipublikasi).

Medan : USU.

ManusiaPerusahaan. Bandung: PT. Remaja Rosda Karya.

\section{Sumber Daya Manusia. Edisi}

Revisi. Cetakan Keenan. Jakarta :

Bumi aksara.

Mangkunegara,

2009. Manajemen

Daya
Anwar Prabu.

Sumber

Manulang, M. 2008. Dasar-Dasar

Manajemen. Yogyakarta: Gajah MadaUniversity

Press.

Moenir, H. A. S, 2007. Manajemen

Pelayanan Umum di Indonesia.

Jakarta : Bumi Aksara.

Purwanto, Djoko. 2006. Komunikasi Bisnis.

Edisi Revisi. Jakarta: Bumi Aksara.

$$
\text { 2011. Komunikasi }
$$

Bisnis. Edisi Kedua. Jakarta:

Erlangga.

Sarah, Jesika. 2011. Pengaruh Komunikasi

Internal Terhadap Prestasi

KerjaKaryawan PT. Telkomsel

Branch Medan. Skripsi (tidak

dipublikasi). Medan : FE USU.

Soewarno Handayaningrat. 2006.

Pengantar Studi Administrasi dan

Manajemen. Jakarta : Gunung Agung.

Subekhi,Akhmad,Mohammad Jauhar. 